\title{
Puerperal breast engorgement: a technological intervention
}

\begin{abstract}
Characterized by pain, edema and increase in breast volume, breast engorgement is one of the most common problems in lactation. An experimental essay was carried out at the Human Milk Bank of a university hospital in Curitiba, Brazil. Sixteen breastfeeding women with lactational engorgement were selected randomly. They were treated by means of massage and milking, manually and electromechanically and breasts temperature were measured, before and after the treatment, in both cases. Thermal asymmetry was found, with a negative temperature gradient of $0.3^{\circ} \mathrm{C}$ between pre and post treatment in the experimental group, showing that electromechanical techniques were superior to manual ones. We concluded that thermography is an effective and promising method to evaluate women with lactational engorgement.
\end{abstract}

Keywords: massage, milking, breastfeeding, breast engorgement, thermography
Volume 3 Issue 6 - 2017

\author{
Anita Batista dos Santos Heberle,' Sandra \\ Marisa Pelloso,' Percy Nohama ${ }^{3}$ \\ 'Universidade Estadual de Maringá (UEM), Brazil \\ ${ }^{2}$ Pontifícia Universidade Católica do Paraná, Brazil
}

Correspondence: Percy Nohama, Graduate Program in

Nursing, Universidade Estadual de Maringá (UEM), Brazil,Tel +55

4| 327|-I357, Fax +55 4| 327|-|357,

Email percy.nohama@pucpr.br

Received: July 24, 2017 | Published: October 03, 2017

\section{Introduction}

Characterized by pain, ${ }^{1}$ edema ${ }^{2}$ and increase in breast volume, ${ }^{3}$ breast engorgement is one of the most common problems in lactation. It occurs mainly by increased vascularization and accumulation of milk and, secondarily, by lymphatic and vascular congestion. ${ }^{2}$ Painful situations encountered by breastfeeding mothers are one of the main causes for the abandonment of breastfeeding in the first weeks after childbirth, ${ }^{2,3}$ fact that can be avoided by means of appropriate approach, using technological resources to massage the breasts and extract the milk. ${ }^{4}$ Massage in engorged breasts complements milking, ${ }^{2}$ as it favors the milk ejection reflex and breaks the intermolecular structures responsible for milk viscosity. ${ }^{5}$ Some authors argue that massage should not injure the underlying skin or tissues. ${ }^{6,7}$

As far as the extraction of milk is concerned, it is a practice that has become increasingly common among breastfeeding mothers, especially in developed countries. Although the technique of manual extraction has been considered by some authors to be a less embarrassing act for the women who breastfeed, the fact is that the emergence of sophisticated dairy pumps adapted for domestic use has attracted breastfeeding mothers who for some reason need to perform the breast milking. ${ }^{8}$ On the other hand, in the centers specialized in human lactation, a technological resource represents a tool, both in the optimization of the time during the care of the lactating woman as well as in the humanization, considering the pain threshold of each woman in the care process. ${ }^{9}$ Also, it is necessary to understand the complexity of the breastfeeding process in order to guarantee optimal conditions for breastfeeding, and to propose measures to protect and promote breastfeeding. ${ }^{10}$ And this is a nursing's role support breastfeeding and research innovative methods to assess and monitor breast engorgement process. In this scenario, emerges the infrared thermography. ${ }^{4}$

Thermography is a technique widely applied in industry and still timidly in the medical field. It acquires the infrared radiation emitted by a body, determining its surface temperature. It allows obtaining thermal images from a temperature above absolute zero. Its potential application in the field of medicine stems mainly from being innocuous. From thermo graphic inspection, differential patterns of the temperature distribution are observed, providing information that may also be related to a certain process that is occurring in the body. ${ }^{12}$ A search in literature indicates that it have not been used in similar studies yet.

The painful events that affect the puerperal breasts are less investigated when compared to those of the non-lactating women, ${ }^{11}$ but with the technological advance, there is a need to expand the knowledge about the physiology of the breast in lactation. Thus, based on the hypothesis that thermography has a high potential for providing information on the physiological aspects of the puerperal breast, it is in the interest of professionals working in human lactation centers to establish protocols for prevention and treatment of certain problems faced by breastfeeding mothers and thereby support evidence-based practice.

Thermography was considered a suitable method when, after the proposed treatments, the thermogram presents altered color patterns (pixel equivalence to temperature) in the thermal distribution and minimum negative temperature gradient of $0.3^{\circ} \mathrm{C}$. Likewise, it was considered thermal asymmetry when between the two breasts of the same woman, there was at least $0.3^{\circ} \mathrm{C}$ difference. This criterion was adopted because it has been applied by other researchers when analyzing other pathologies, ${ }^{13}$ although the literature also considers thermal asymmetry, starting at $0.5^{\circ} \mathrm{C} .{ }^{14}$ The goal of the present study was to evaluate the treatment of lactational breast engorgement by means of thermogram.

\section{Methodology}

This clinical survey, with a quantitative and qualitative approach, was carried out at the Human Milk Bank -HMB of a hospital in Curitiba, Brazil. Sixteen women with lactational engorgement were randomly selected and divided into two groups: eight in the experimental group and eight in the control group. For the sample, the population of women treated at the HMB was considered. With an error tolerance of $7 \%$ and a $95 \%$ confidence level, a prevalence of $50 \%$ was initially estimated, with a need of 196 volunteers. Statistical significance was set at $5 \%$. It should be emphasized that the sample was impaired by the availability of the instruments used in this study. 
The lactating mothers were recruited by a nurse with extensive experience in breastfeeding. The inclusion criteria were: infants between the $3^{\text {rd }}$ and $10^{\text {th }}$ day of the puerperium; 18 yo. and older, and women with bilateral engorgement of any classification as to their intensity or location in the breast. ${ }^{4}$ Exclusion criteria were: lactating mothers with a history of palpable or non-palpable breast lesion, mammoplasty and/or use of breast implants, previous history of lactational mastitis, breast pain, or analgesic use less than two hours before the study.

For each breastfeeding woman, the type of treatment to be performed was drawn using the coin-throw method. With the result "face", the first volunteer was allocated in the control group and received treatment through manual massage and milking. With a "crown" result, the volunteer was allocated in the experimental group and received treatment by electromechanical techniques, beginning with the left breast. Thus, the treatment techniques were alternated, from the first draw.

The volunteers were evaluated by thermography. In this way, the differential temperature patterns, before and after the treatment, which consisted of massage and milking by manual and electromechanical techniques, were compared. Thus, before and after treatment, they remained with their breasts uncovered for $15 \mathrm{~min}$ in an environment of $7.5 \mathrm{~m}^{2}$ thermally controlled at $23^{\circ} \mathrm{C}$ and $50 \%$ relative humidity, monitored by the manufacturer's digital thermo-hygrometer model 7645 Incoterm.

For the treatment of engorged breasts, massage and milking were performed using manual techniques for the control group and electromechanical techniques for the experimental group. For the electromechanical techniques, vibratory massage equipment made by the Brazilian Industry Physical, in the mode of higher vibration, was applied; and the Medelar swiss-made milk pumps, on maximum suction mode.

The volunteers signed a free and informed consent form after the approval of the research project by the Research Ethics Committee with Human Beings of the Pontifical Catholic University of Paraná (register number 5863). Data were entered in Excel spreadsheet, and we used the SAS 9.1 software in the statistical analysis. For the analysis of the images, FLIR Systems Inc.'s Therma CAM ${ }^{\mathrm{TM}}$ Software 2.9 was applied.

\section{Results and discussion}

In this research, the temperature of the breasts was measured and compared to both control and experimental groups, before and after treatment, in order to identify temperature differences among them. T-paired test was applied, whose p-values results are presented in Table 1. It was found that there was a significant difference between the temperature variations considering the pre- and post-treatment moments in the experimental group. In the control group, there was no significant difference.

Table I Temperature comparison between the control group and the experimental one, before and after treatment

\begin{tabular}{llll}
\hline Group & $\begin{array}{l}\text { Mean temperature } \\
\text { before treatment }\left({ }^{\circ} \mathrm{C}\right)\end{array}$ & $\begin{array}{l}\text { Mean temperature } \\
\text { after-treatment }\left({ }^{\circ} \mathrm{C}\right)\end{array}$ & P-value \\
\hline Control & 35.2 & 35.3 & 0.8153 \\
Experimental & 34.8 & 34.5 & 0.0349 \\
\hline
\end{tabular}

Thermal asymmetry was observed with a negative temperature gradient of $0.3^{\circ} \mathrm{C}$ between pre- and post-treatment in the experimental group, showing that electromechanical techniques were superior to manual techniques. Although it was not a study variable, the lactating mothers of the experimental group stated that the application of the electromechanical technologies in solving the breast engorgement constitute a less painful process when compared to the manual techniques they were accustomed to.

Figure 1 shows the anteroposterior thermograms of a woman with bilateral intense glandular engorgement (volunteer number 5). After electromechanical massage, she presented easy drainage during milking. The breasts became soft after treatment and during the rest period they remained loose as recommended by the proposed protocol. However, there was exaggerated synthesis of milk and the breasts refilled during the rest period. They presented a temperature of $35.4^{\circ} \mathrm{C}$ before the intervention and $35.8^{\circ} \mathrm{C}$ after the treatment, with a positive variation of $0.4^{\circ} \mathrm{C}$. It is observed qualitatively a E-type nipple colder (black color) if compared to the body of the breast. ${ }^{15}$

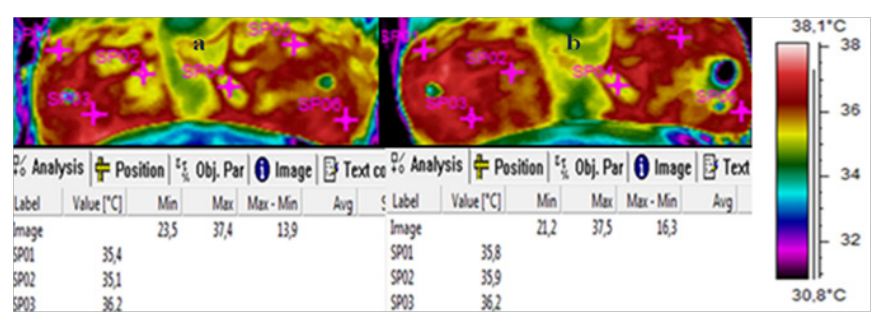

Figure I Breasts thermograms of the volunteer number 5, with bilateral intense glandular engorgement. In (A), the breasts before treatment and in (B), the breasts that were filled during the rest time and $E$ type nipple with the lowest temperature (Hainhi palette).

In a study of Silva ${ }^{16}$ an electrical massager was used to treat breast engorgement and it was concluded that besides being painless and not causing discomfort to the nursing mothers, the equipment has provided relief, relaxation and rapid milk outflow. ${ }^{16}$ Although other studies have not clearly shown the extraction method preferred by women, interventions that promote relaxation and support are measures that provide greater satisfaction. ${ }^{15}$ In this sense, Silva suggested the development of technologies within this care field, since women should be seen as a whole. ${ }^{16}$ If the breastfeeding mother receives adequate attention to her needs, this will be reflected in the child because it will naturally also satisfactorily meet the needs of your child. It is necessary to understand the complexity of the breastfeeding process in order to guarantee optimal breastfeeding conditions for the mother. From this understanding, it will be possible to propose measures of protection and promotion to breastfeeding. ${ }^{10}$ For milk extraction, a review study has shown that manual milking and electric pumps are more effective in protein production compared to manual pumps. The lipid content was also higher with simultaneous massage during milk extraction. In this perspective, nutrient variation among extraction methods may be relevant for some children. ${ }^{15}$

The experimental group, although showing a decrease in the temperature pattern, one of the mothers had exacerbated production, and refilled, soon after the treatment. It was also observed that after the use of the electric pump, the left nipple was hypoxic and colder, denoting vasoconstriction. It is noteworthy that the asymmetry in the pattern of nipple color and temperature, also occurred by extravasation of milk during the ejection reflex. However, there was improvement in the nipple perfusion, shortly after image capture. Our results suggest 
that women with areolar edema should avoid this form of extraction, considering the propensity for nipple trauma, decreased lumen of the ducts and worsening of edema, especially in women with obstructive glandular-type breast engorgement.

\section{Conclusion}

In this study, it was verified that the mechanical stimuli on mammary tissues, caused by the massage, promoted considerable physiological effects in the breasts with intense breast engorgement. There was an increase in the local cutaneous microcirculation, measured by thermography. Also, it showed that the massage associated with milking has promoted the transit of milk that was "stoned". It was verified that the massage caused the thermal increase in the breasts, favoring the milk extraction. The present research points to electromechanical massage and milking as superior to manual techniques, both for quantitative reduction of breast temperature as for adequate clinical management of lactational breast engorgement. The immediate use of the brassiere as soon as finish the extraction of milk can prevent new engorgement. Therefore, it is recommended not to use this method of milk extraction in infants with nipple trauma or with Raynaud's Phenomenon.

\section{Acknowledgements}

None.

\section{Conflict of interest}

The author declares no conflict of interest.

\section{References}

1. Witt AM, Bolman M, Kredit S, Therapeutic breast massage in lactation for the management of engorgement, plugged ducts, and mastitis. J Hum Lact. 2016;32(1):123-131.

2. Berens P, Brodribb W. ABM Clinical Protocol\# 20: Engorgement, Revised 2016. Breastfeeding Med. 2016;11(4):159-163.

3. Jacobs A, Abou-Dakn M, Becker K, et al. S3-guidelines for the treatment of inflammatory breast disease during the lactation period. Geburtshilfe Frauenheilkd. 2013;73(12):1202-1208.
4. Heberle ABS, Moura MAM, Souza MA, et al. Assessment of techniques of massage and pumping in the treatment of breast engorgement by thermography. Revista Latino-Americana de Enfermagem. 2014;22(2):277285 .

5. Almeida JAG. Amamentação: um híbrido natureza - cultura. Rio de Janeiro: Springer; 1999.

6. Lang S. Aleitamento do lactente cuidados especiais. São Paulo: Livraria e Editora Santos; 1999. pp. 180.

7. Mori T. Método para realizar a massagem de mama. Maringá: Produção de Garcia Vídeo e Foto Produções; 2007.

8. Johns HM, Forster DA, Amir LH, et al. Prevalence and outcomes of breast milk expressing in women with healthy term infants: a systematic review. BMC pregnancy and childbirth. 2013;13(1):212.

9. Heberle ABS. Uma Contribuição Tecnológica para o Manejo e Investigação do Ingurgitamento mamário na Lactação. Dissertação (Mestrado). Pontifícia Universidade Católica do Paraná, Brazil: Springer; 2012.

10. Amaral LJX, Sales SDS, Carvalho DPDSR, et al. Factors that influence the interruption of exclusive breastfeeding in nursing mothers. Revista gaucha de enfermagem. 2015;36(SPE):127-134.

11. Heberle ABS, Ichisato SMT, Nohama P. Breast evaluation during lactation using thermography and pressure algometry. Acta Paulista de Enfermagem. 2015;28(3):256.

12. Côrte ACR, Hernandez AJ. Application of medical infrared thermography to sports medicine. Revista Brasileira de Medicina do Esporte. 2016;22(4):315-319.

13. Papaléo RM, Teixeira MJ, Brioschi ML. Infrared thermography to evaluate pain in a multiple sclerosis patient: Case report. Revista Dor. 2016;17(3):232-235.

14. Chudecka M, Lubkowska A, Leźnicka $\mathrm{K}$, et al, The use of thermal imaging in the evaluation of the symmetry of muscle activity in various types of exercises (symmetrical and asymmetrical). J Hum Kinet. 2015;49(1):141-147.

15. Becker GE, Smith HA, Cooney F. Methods of milk expression for lactating women. Cochrane Database Syst Rev. 2015;12:CD006170.

16. Silva IA. Inovação no tratamento do ingurgitamento mamário - o uso do vibrador elétrico para massagens. Acta Paulista de Enfermagem. 1996;9(1):61-70 